\title{
Effects of Ethanolic Leaf Extract of Solenostemon Monostachyus on Blood Glucose level and Histopathological Parameter in STZ-Induced Diabetic Wistar Albino Rats
}

\author{
Dennis Amaechi*, EO Udosen, EE Edet, PE Nelson and OV Okonkwo \\ Biochemistry Department, Faculty of Basic Medical Sciences, University of Calabar, Nigeria
}

Submission: June 06, 2017; Published: July 06, 2017

*Corresponding author: Dennis Amaechi, Biochemistry Department, Faculty of Basic Medical Sciences, University of Calabar, Nigeria, Tel: +2348037589752; Email: amaechitoexcel@yahoo.com

\begin{abstract}
The effects of ethanolic leaf extract of Solenostemon monostachyus on blood glucose level and histopathological parameter was assessed on STZ induced diabetic Wistar albino rats. A total of 24 rats were used in this research study, six of them were placed as normal control, six as diabetic control, six as insulin treated group and six as Solenostemon treated group. Following treatment for 21 days with the extract, the serum glucose level $(\mathrm{mg} / \mathrm{dl})$ were $(70.00 \pm 10.50)$ for SM treated group $(256.00 \pm 15.00)$ for $\mathrm{DC}(\mathrm{P}<0.05)$. Histopathological studies revealed remediation of damaged kidney and the liver of diabetic animals treated with the extract.

Abbreviations: STZ: Streptozotocin; FBS: Fasting Blood Sugar; DMSO: Dimethylsulfoxide; ANOVA: Analyzed by one-way analysis of variance; NC: Normal Control; DC: Diabetic Control; SM: Solenostemon monostachyus; H: Hepatocytes; BS: Bowman’s space; T: Tubules; G: Glomeruli; CV: Central Vein; PT: Portal Tracts
\end{abstract}

\section{Introduction}

One of the most dangerous and life threatening diseases in the world today, involving the pancreas, is diabetes mellitus [1]. It is a condition primarily defined by the level of hyperglycemia giving rise to risk of micro vascular damage (retinopathy, nephropathy and neuropathy). It is associated with reduced life expectancy, significant morbidity due to specific diabetes related micro vascular complications, increased risk of macro vascular complications (ischemic heart disease, stroke and peripheral vascular disease) and diminished quality of life [2]. The record of its prevalence in the world today and the increase in morbidity and mortality rates calls for an urgent attention from the health professionals and policy makers in tackling this disease. In CôtedIvoire, the rate of morbidity is 5.7\%. Traditional medical herbs used for strengthening the body immune system and for therapeutic purposes are known to have many essential and nutritional elements. Many plants have been documented to have the efficacy to treat diabetes in CôtedIvoire [3].

Diets rich in fruits, cereals and vegetables have been shown to play a crucial role in the prevention of a lot of disorders such as cardiovascular diseases, certain cancer types and even ageing
$[4,5]$. Thus efforts have been made towards the elucidation of bioactive potentials of many plants of recent. This has however not translated to utilization of these plants coupled with the fact that the bioactive potentials of a lot of them are yet to be investigated. Solenostemon monostachyus sp. Beauv (family Lamiaceae), common name (African dead nettle), Effik name (Ntorikwot, Awakmmon) is an important herb that is widespread in West and central Africa. It occurs as an annual weed in anthropogenic habitat and rocky savannahs. It is slightly succulent, aromatic and grows up to $100 \mathrm{~cm}$ tall [6].

It has been reported that plant has been traditionally used in the past for ritual purposes related to pregnancy. The decoction of the leaves is also taken as a diuretic [7]. Research has also shown that the leaves possess antimicrobial activity [8]. (The health promoting properties of plants are ascribed to the possession of various photochemical especially phenolics and this beneficial activity is related to their antioxidant activity [9]. Herbal medicine has improved as alternative effective solution to health problems and cost of pharmaceutical products. However, little work has been done to match ethanobotanical information with analytical research to identify active chemical compounds. 


\section{Anatomy Physiology \& biochemistry international journal (APBIJ)}

Plants used in traditional medicine can offer potential sources of new biological active compounds, many of them as antidiabetic, anti-HIV, and antifungal agents. Examples of these compounds include flavonoids, sapononins, phenolics, glucosinolates, and cynagenic glycosides [10]. (Potential natural or synthetic substances with biocide activity are considered candidates for developing new drugs for the treatment of various chronic as well as infectious diseases. Indigenous medicinal plants continue to be rich source of therapeutic drugs. The active principles of many drugs are usually found in plants as secondary metabolites. The search for new pharmacologically active agents obtained by screening natural sources such as microbial fermentations and plant extracts has led to the discovery of many clinically useful drugs that play a major role in the treatment of human diseases (Figure 1).

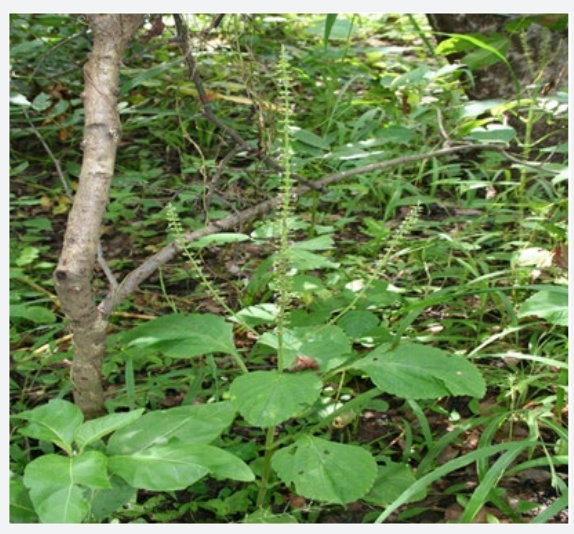

Figure1: Picture of Solenostemon monostachyus.

\section{Materials and Method}

Chemicals and Reagents: Several chemicals and analytical grade reagents were purchased, and used for this research which includes: Ethanol (98\%), sodium hydroxide, sodium chloride and glucometer strips which were purchased from Globus Chemical, Mayne Avenue, Calabar, and Cross River State, Nigeria. The beta cell destructive agent, streptozotocin (STZ) was obtained from sigma, St. Louis, MO, U.S.A.

The routine assay kits for glucose, total protein, albumin, the amino-transferase, urea, were purchased from Randox Laboratories Ltd. And more Diamond road, Crumlin, Co Antrim United Kingdom, Bt294QY. Kits for high density lipoprotein, total cholesterol, triacylglycerol, chloride, calcium, phosphorus were obtained from Dialab Production and laborinstriementen Gessellschaft M.b.H. A - 1160 Wien-panikengasse, Austria. Whereas sodium and potassium kits were obtained from Teco Diagnostics 1268N. Lakeview Ave. Anaheim, CA 92807, U.S.A, insulin injection (NPH, Humulin) needles and other syringes used were obtained from Karmel Pharmacy, Goldie Street, and Calabar while EDTA tubes were obtained from Meditec Laboratory, 91 White House, Calabar.
Identification and preparation of Plant Materials: Fresh leaves of Solenostemon monostachyus were collected from local garden at the University of Calabar, Nigeria. The sample of the plant specimen was identified and authenticated by a Botanist from the botanical garden, and the Voucher specimen was deposited in the herbarium of the same University. The leaves were sorted to eliminate any dead matter and other unwanted particles. The leaves were air-dried for 2 weeks and the leaves were blended with a manual hand blender and $150 \mathrm{~g}$ of the plant was weighed and soaked in $700 \mathrm{ml}$ of ethanol. The mixture was then placed in a water bath at about $60-80^{\circ} \mathrm{C}$ for 10 minutes for through extraction of the plant active component and allowed to cool. The extract was then filtered with a chess material and later a watchman no 1 filter paper to obtain a homogenous filtrate. The filtrate was then concentrated in vacuum at low temperature of $37-40^{\circ} \mathrm{C}$.

The concentrate was then allowed open in a water bath for complete dryness. The extract was refrigerated at $2-5^{\circ} \mathrm{C}$ until when used. Appropriate concentration of the extract was subsequently made by dilution with distilled water into 250/ $\mathrm{mg} / \mathrm{kg}$ body weight and administered to the animals (Table 1 ).

Table 1: Animal groupings and treatment schedule/ protocol.

\begin{tabular}{|c|c|c|c|}
\hline $\mathbf{S} / \mathbf{n}$ & Groups & $\begin{array}{c}\text { Number of } \\
\text { rats }\end{array}$ & Treatment/vehicle \\
\hline 1. & $\begin{array}{c}\text { Normal control } \\
\text { (NC) }\end{array}$ & 6 & $\begin{array}{c}50 \% \text { DMSO and } \\
\text { distilled water }\end{array}$ \\
\hline 2. & $\begin{array}{c}\text { Diabetic control } \\
\text { (DC) }\end{array}$ & 6 & $\begin{array}{c}50 \% \text { DMSO and } \\
\text { distilled water }\end{array}$ \\
\hline 3. & $\begin{array}{c}\text { Insulin treated } \\
\text { group (INS) }\end{array}$ & 6 & $\begin{array}{c}\text { Insulin (5 unit } / \mathrm{kg} \\
\text { b.w) }\end{array}$ \\
\hline 4. & $\begin{array}{c}\text { Solenostemon } \\
\text { monostachyus } \\
\text { treated group } \\
\text { (SM) }\end{array}$ & 6 & $\begin{array}{c}\text { Extract (250 } \mathrm{mg} / \mathrm{kg} \\
\text { b.w) }\end{array}$ \\
\hline
\end{tabular}

Handling and treatment of Animals: A total of 24 adult male albino rats weighing between 150-250g obtained from the disease free stock of the animal house, Biochemistry Department, College of Medical Sciences University of Calabar, Nigeria, were used for the study. The rats were divided into four groups with six rats each, as follows: Group A (normal control group receiving distilled water as placebo), Group B (diabetic control group receiving distilled water as placebo), Group C (insulin group receiving $5^{\mathrm{U}} / \mathrm{kg}$ bodyweight of insulin). Group D (diabetic test group will received oral dose of Solenostemon monostachyus leaves extract juice).

Induction of experimental diabetes: Prior to diabetes induction, the rats were subjected to $12 \mathrm{hr}$ fast, and then diabetes was induced by intraperitoneal injection of $40 \mathrm{mg} / \mathrm{kg}$ b.w. with streptozotocin (STZ) (sigma St. Louis, Mo, U.S.A) using sodium citrate buffer $(0.5 \mathrm{M})$ reconstituted in dimethylsulfoxide (DMSO). The normal control animals received DMSO only, three days after 


\section{Anatomy Physiology \& biochemistry international journal (APBIJ)}

STZ treatment, diabetes was confirmed in STZ treated rats with a fasting blood sugar (FBS) concentration $\geq 200 \mathrm{mg} / \mathrm{dl}$. This was estimated using One Touch Glucometer (Life scan, Inc. 1996 Milpas, California, U.S.A) with blood obtained from the tail vein of the rats.

The rats were acclimatized in the experimental animal house for one week before the commencement of the experiment. The animals, housed in stainless steel cages under standard conditions (ambient temperature, 28.0 $\pm 2.0^{\circ} \mathrm{C}$ and humidity, $46 \%$, with a $12 \mathrm{hr}$ light/dark cycle), were fed with the normal rat pellets. All the rats in both test and control groups were allowed free access to food and water ad libitum, throughout the experimental period. Good hygiene was maintained by constant cleaning and removal of faeces and spilled feed from cages daily. The animals in test groups III will received insulin $5^{\mathrm{v}} / \mathrm{kg}$ body weight and IV will received oral daily doses of aqueous extract of Solenostemon monostachyus leaves respectively, using orogastric tubes and syringes.

This lasted for a period of 21 days and the experiments were conducted between the hours of 7.00 am and 7.00 pm daily. Rats in the control groups I were administered, by oral gavage, with $5 \mathrm{ml}$ of distilled water (placebo). All the animal experiments were carried out in accordance with the guidelines of the Institution's Animal Ethical Committee.

Collection and analysis of blood: All the animals were anaesthetized with chloroform vapor, twenty-four (24) hours after last day of extract administration, and dissected for blood collection. Blood samples were collected by cardiac puncture into a set of plain and fluoride oxalate sample bottles. Determination of LD50/Acute toxicity tests. This was done orally using albino mice. Biochemical tests were carried out, which include: liver enzymes-alanine aminotransferase and aspartate aminotransferase according to the method described by Reithman (1957). Serum alkaline Phosphatase using Randox test kits. Lipoprotein profile-Total cholesterol, HDL-C, TG, serum electrolytes, urea and creatinine

Statistical Analyses: The results obtained from this study were analyzed by one-way analysis of variance (ANOVA), followed by Student's t-test to evaluate the significance of the difference between the mean value of the measured parameters in the respective test and control groups using SPSS windows. A significant change was considered acceptable at $\mathrm{P}<0.05$.

\section{Results}

Changes in blood glucose of diabetic and non-diabetic test animals: Daily changes in blood glucose that was monitored following daily treatment with extract and insulin in diabetic and non-diabetic rats. The blood glucose levels ranged between 60- $108 \mathrm{mg} / \mathrm{dl}$ in the normal control rats (NC) that were not given any extract. Fasting blood glucose of other treatment groups varied differently, the treatment groups tended toward lowering the blood glucose levels when compared with the diabetic control (DC), but the Solenostemon monostachyus (SM) group was closely related to the insulin treated group. The diabetic control group range was between 601 and $295 \mathrm{mg} / \mathrm{dl}$. Differences in DC showed sustained elevations in blood glucose level of untreated diabetic rats (Table 2).

Table 2: Effect of treatment on glucose levels in blood and serum.

\begin{tabular}{|c|c|c|c|}
\hline $\begin{array}{c}\text { Group/ } \\
\text { Treatment }\end{array}$ & $\begin{array}{c}\text { Initial FBG } \\
\mathbf{( m g / d l )}\end{array}$ & $\begin{array}{c}\text { Final FBG } \\
\mathbf{( m g} / \mathbf{d l})\end{array}$ & $\begin{array}{c}\text { Serum } \\
\text { Glucose (mg/ } \\
\mathbf{d l})\end{array}$ \\
\hline NC & $74.83 \pm 8.92$ & $90.50 \pm 6.20$ & $57.14 \pm 8.12$ \\
\hline DC & $539.33 \pm 14.13^{*}$ & $323.00 \pm 8.58^{*}$ & $256.00 \pm 15.00^{*}$ \\
\hline INS & $433.33 \pm 32.24^{*} \mathrm{a}$ & $82.33 \pm 2.47 \mathrm{a}$ & $54.93 \pm 2.32 \mathrm{a}$ \\
\hline SM & $297.25 \pm 57.69 * a$ & $191.33 \pm 4.94 \mathrm{a}$ & $70.00 \pm 10.50 \mathrm{a}$ \\
\hline
\end{tabular}

Values are expressed as mean \pm SEM

*significantly different from NC at $p<0.05$

$a=$ significantly different from $D C$ at $p<0.05$

$b=$ significantly different from INS at $p<0.05$

$c=$ significantly different from SM at $p<0.05$

Effect of treatment on the histological architecture of liver and kidney tissues using Haematoxylin and Eosin technique

Figure 2: Photomicrographs of liver of normal control group showing preserved architecture with dilated and congested central vein, prominent radiating hepatocytes from the central vein, prominent sinusoidal spaces and portal tracts (bile duct, portal vein and hepatic arteries).

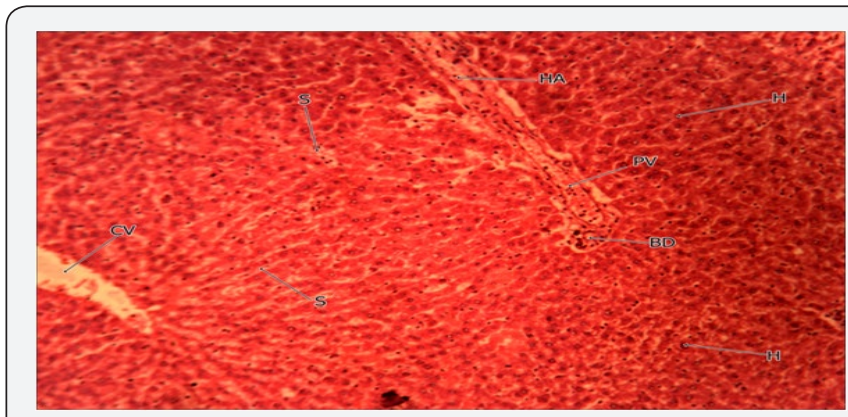

Figure 2: Photomicrographs of liver of normal control (NC) group treated with $50 \%$ DMSO showing preserved architecture with dilated and congested central vein $(\mathrm{CV})$ prominent radiating hepatocytes (PRD) from the central vein, prominent sinusoidal spaces (PSS) and portal tracts (PT).

Method: Haematoxylin \& Eosin staining. Magnification x 100

Figure 3: Photomicrographs of kidney section of normal control group showing distinct cortex and medullar with numerous renal tubules lined with cuboidal - columnar cells with a distinct lumen, prominent glomeruli and Bowman's space, as well as hyper cellular mesangium. 


\section{Anatomy Physiology \& biochemistry international journal (APBIJ)}

Figure 4: Photomicrographs of liver of diabetic control group showing patchy necrotic sections of liver tissue, atrophic hepatocytes $(\mathrm{H})$ with deeply stained pyknotic nuclei.

Figure 5: Photomicrographs of kidney of diabetic control group showing atrophic and degenerated glomeruli (G) with a hypocellular mesangium and reduced Bowman's space (BS). The tubules ( $\mathrm{T}$ ) also showed detachment of the epithelial lining from their basement membrane forming red cast.

Figure 6: Photomicrographs of liver of insulin-treated control group showing preserved architecture, prominent central vein $(\mathrm{CV})$, radiating cords of hepatocytes $(\mathrm{H})$ and portal tracts (PT) indicating no pathology.

Figure 7: Photomicrographs of kidney of insulin-treated group showing a distinct cortex and medulla, numerous glomeruli (G) with prominent Bowman's capsule (BS). Some glomeruli showed hyalinized mesangium that is a cellular and some show glomerulosclerosis. The cortical renal tubules had a patent surrounded by deeply stained cuboidal epithelium. No severe pathology.

Figure 8: Photomicrographs of liver of Solenostemon monostachyus-treated control group showing preserved liver architecture consisting of hexagonal lobules of radially radiating hepatocytes $(\mathrm{H})$ with slightly congested central vein (CV) prominent sinusoidal spaces $(\mathrm{S})$ and moderate pyknotic nuclei. Mild peripheral inflammatory cell infiltrates were also seen indicating no severe pathology.

Figure 9: Photomicrographs of kidney of M-treated group showing numerous atrophic glomeruli with prominent Bowman's capsules, dense acellular mesangium and glomeruli. The cortical tubules have ghost-like appearance with prominent lumen and intensely stained atrophic cells with scanty interstitium. Mild pathology. The histological and/or architectural integrity of the liver and kidney tissues in the experimental group was examined and compared with the controls. Results revealed that for liver tissues there was no evidence of liver cell injury for the controls, because sections of the liver tissues showed a preserved architecture with dilated and congested central veins. The hepatocytes were prominent and radiated from the central vein. The hepatic cells had an eosinophilic cytoplasm and ovalto-ovoid basophilic nuclei. The sinusoidal spaces are prominent and contain portal tracts were prominent and contain the bile duct, portal vein and hepatic arteries.

For normal control kidney, there was no indication of kidney lesion since sections of the kidney showed a distinct cortex and medulla. The Glomeruli were prominent with a distinct Bowman Space. The mesangium was hypercellular and with abundant interstitium. The medulla consisted of numerous renal tubules of various sizes and shapes. The tubules were lined with cuboidal to columnar epithelium with a distinct lumen (Figure 3).

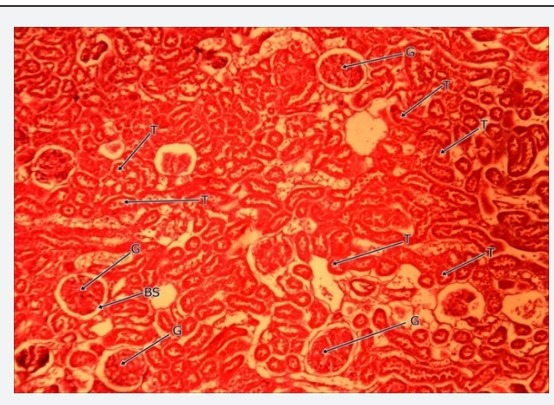

Figure 3: Photomicrographs of kidney section of normal control(NC) group treated with $50 \%$ DMSO showing distinct cortex and medullar with numerous renal tubules(RT) lined with cuboidal - columnar cells with a distinct lumen(DL), prominent glomeruli (PG) and Bowman's space(BS), as well as hyper cellular mesangium.

Method: Haematoxylin \& Eosin staining. Magnification x 100

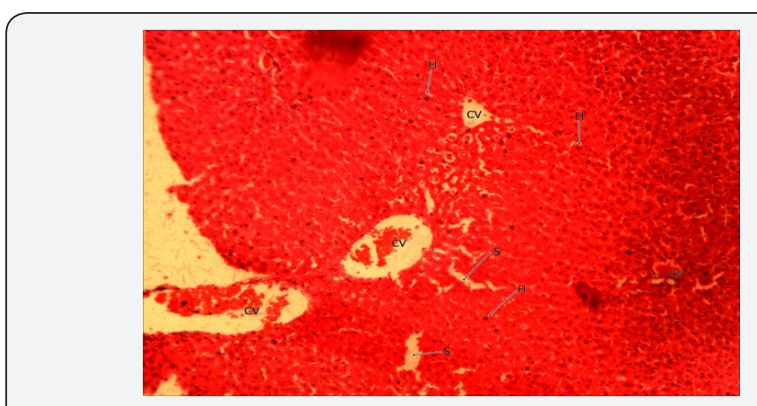

Figure 4: Photomicrographs of liver of diabetic control (DC) group treated with $50 \%$ DMSO showing patchy necrotic sections of liver tissue, atrophic hepatocytes (AH) with deeply stained pyknotic nuclei.

Method: Haematoxylin \& Eosin staining.Magnification x 100

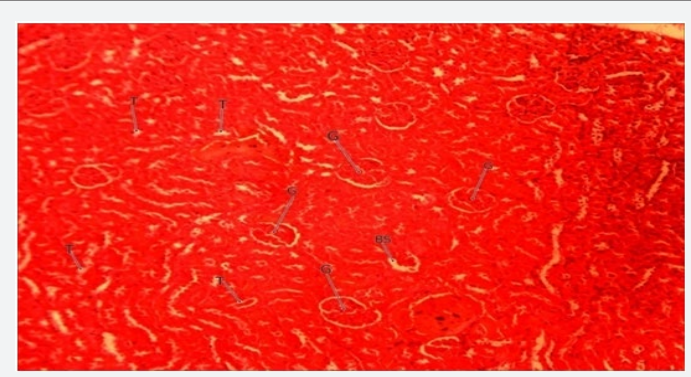

Figure 5: Photomicrographs of kidney of diabetic control (DC)group DMSO treated with $50 \%$ showing atrophic and degenerated glomeruli (DG) with a hypo cellular mesangium and reduced Bowman's space(RBS). The tubules (T) also showed detachment of the epithelial lining from their basement membrane forming red cast.

Method: Method: Haemotoxylin \& Eosin staining, Magnification $\mathrm{x} 100$

Diabetic control (DC) liver revealed patchy necrotic section of liver tissues showing prominent dilated and congested central veins, atrophic hepatocytes with deeply stained hepatocytes having pyknotic nuclei. Diabetic control (DC) also revealed sections of the kidney showing atrophic and degenerated 


\section{Anatomy Physiology \& biochemistry international journal (APBIJ)}

glomeruli which were oedematous with reduced Bowman space. The tubules showed detachment of the epithelial lining from their Basement membrane forming red cast. The medulla consisted of numerous renal tubules lined by cuboidal epithelial cells. This indicated a degree of pathology (Figures $4 \& 5$ ).

In diabetic treated groups, there were varied levels of improvement as the liver and kidney cell architecture gradually returned to normal in the different treatment groups. For the insulin group, INS, sections of the liver showed tissues with a preserved architecture showing prominent congested central vein, dilated sinusoidal space and portal tract consisting of Bile duct, Hepatic artery, Portal vein and mild mononuclear cellular infiltrates. The hepatocytes are radically running from the central veins. They have prominent round-to-oval basophilic nuclei and abundant eosinophilic cytoplasm, thus indicating no pathology to the liver tissues.

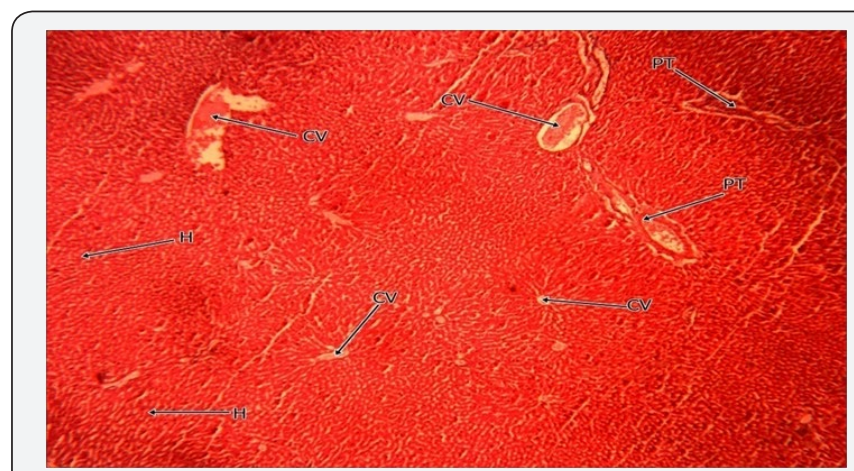

Figure 6: Photomicrographs of liver of insulin-treated (INS) control group treated with 5 Unit/kg b.w insulin showing preserved architecture, prominent central vein $(\mathrm{CV})$, radiating cords of hepatocytes $(\mathrm{H})$ and portal tracts $(\mathrm{PT})$ indicating no pathology.

Method: Method: Haemotoxylin \& Eosin staining, Magnification x 100

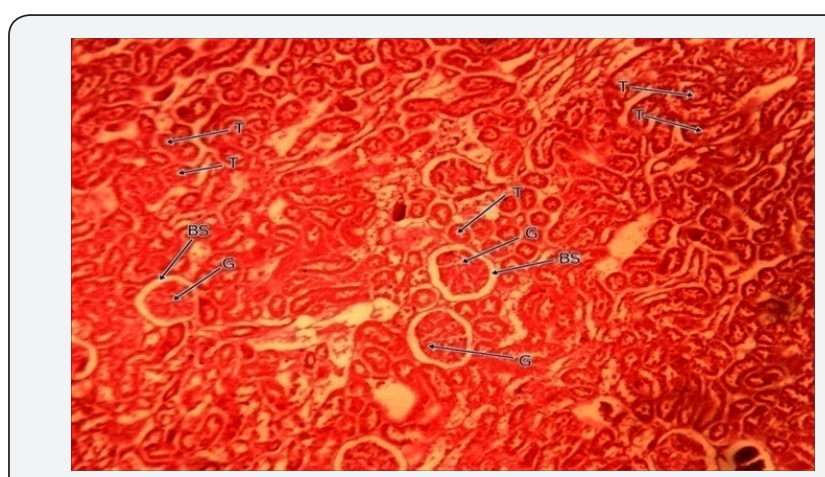

Figure 7: Photomicrographs of kidney of insulin-treated (INS) group treated with 5 Unit/kg b.w insulin showing a distinct cortex and medulla, numerous glomeruli $(\mathrm{G})$ with prominent Bowman's capsule (PBS). Some glomeruli showed hyalinized mesangium that is a cellular and some show glomerulosclerosis. The cortical renal tubules had a patent surrounded by deeply stained cuboidal epithelium. No severe pathology.

Method: Method: Haematoxylin \& Eosin staining, Magnification x 100
The kidney tissues for INS revealed a section showing a distinct cortex and medulla. Numerous glomeruli showed as hyalinized mesangium that is acellular and some show glomerulosclerosis. Majority of the glomeruli were viable. The cortical renal tubules had a patent lumen surrounded by deeply stained cuboidal epithelium. The intervening interstitium was sparse. The medulla consisted of numerous collecting tubules of various sizes and shapes lined by an intact epithelium (Figures $6 \& 7)$.

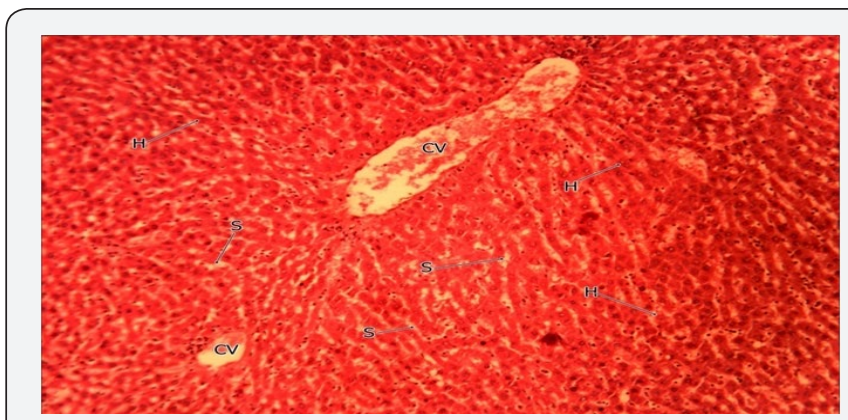

Figure 8: Photomicrographs of liver of Solenostemon monostachyus (SM)-treated group with $250 \mathrm{mg} / \mathrm{kg}$ b.w extract showing preserved liver architecture consisting of hexagonal lobules of radially radiating hepatocytes $(\mathrm{H})$ with slightly congested central vein (CV) prominent sinusoidal spaces (SS) and moderate pyknotic nuclei. Mild peripheral inflammatory cell infiltrates were also seen indicating no severe pathology.Method: Method: Haematoxylin \& Eosin staining, Magnification x 100

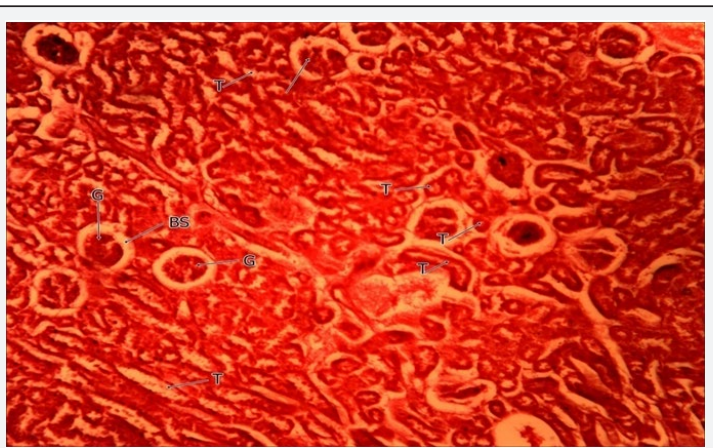

Figure 9: Photomicrographs of kidney of Solenostemon monostachyus (SM)-treated group with $250 \mathrm{mg} / \mathrm{kg}$ b.w extract showing numerous atrophic glomeruli with prominent Bowman's capsules (PBS), dense acellular mesangium and glomeruli. The cortical tubules (CT) have ghost-like appearance with prominent lumen and intensely stained atrophic cells with scanty interstitium, Mild pathology.

Method: Method: Haematoxylin \& Eosin staining, Magnification $x 100$

Solenostemon monostachyus group, SM histology showed sections of the liver tissues with preserved architecture consisting of hexagonal lobules having a central vein and radically displayed hepatocytes. The hepatocytes had moderate oesinophilic cytoplasm and pyknotic nuclei. The central veins were slightly congested and the sinusoidal spaces were prominent. Thus mild peripheral inflammatory cell infiltrates 
were seen. For section of the kidney tissue in this Solenostemon monostachyus (SM) group numerous atrophic glomeruli with prominent Bowman capsules and dense oesinophilic a cellular mesangium and glomeruli were seen. The cortical tubules had a ghostlike appearance with prominent lumen and intensely stained atrophic cells. The intervening interstitium was scanty (Figures 8 \& 9).

\section{References}

1. Verbrugge LM, JM Lepkowski, Y Imanaka (1989) Comorbidity and its impact on disability. Milbank Quater 67(3-4): 450-484.

2. World Health Organization (2006) Definition and Diagnosis of Diabetes Mellitus and Intermediate Hyperglycaemia. Geneva: World Health Organization p. 1-50.

3. Aké A, Adjanohoun E (1979) Contribution to document medicinal plants in Côte d'Ivoire Centre Nat. Florist. Univ Abidjan.

4. Joshipura KJ, Hu FB, Manson JE, Stampfer MJ, Limm FB, et al. (2001) The effect of fruit and vegetables intake on the risk for coronary heart diseases. Ann Inter Med 134(12): 1106-1114.

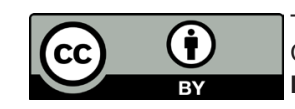

This work is licensed under Creative Commons Attribution 4.0 Licens DOI:10.19080/APBIJ.2017.02.555600
5. Eyele Mve-Mba, Menut C (1994) Aromatic plants of tropical Central Africa. Flavanoid Fragrance Journal 9(6): 315-317.

6. Koffi N, Marie Solange T, Emma AA, Noel ZG (2009) Ethnobotanical study of plants used to treat Arterial Hypertension, in traditional Medicine, by Abbey and Krobou populations of Agboville (Coted'Ivoire). European Journal of Science Resources 35: 85-98.

7. Ekundayo EO, Ezeogu LI (2006) Evaluation of antimicrobial activities of extracts of five Plants used in traditional medicine in Nigeria. International Journal of Tropical Medicine1: 93-96.

8. Heim KE, Tagliaferro AR, Bobilya DJ (2002) Flavanoid antioxidants: chemistry, metabolism And structure - activity relationships. Journal of Nutritional Biochemistry 13(10): 572-584.

9. Bennett RN, Wallgrove RM (1994) Secondary metabolite in plant defense mechanism. New phytology 127(4): 617-633.

10. Aruoma OI (2003) Methodological consideration for characterizing potential antioxidant actions of bioactive compounds in plants foods. Mutual Resource 9(2): 523-524.

Your next submission with Juniper Publishers will reach you the below assets

- Quality Editorial service

- Swift Peer Review

- Reprints availability

- E-prints Service

- Manuscript Podcast for convenient understanding

- Global attainment for your research

- Manuscript accessibility in different formats

( Pdf, E-pub, Full Text, Audio)

- Unceasing customer service

Track the below URL for one-step submission https://juniperpublishers.com/online-submission.php 